REVIEW ARTICLE

\title{
Impact evaluation of schistosomiasis control into elimination interventions models in P. R. China and Africa
}

\author{
Ernest Tambo ${ }^{1,2}$, Jia Tei-Wu ${ }^{3,4}$, Xiao Ning ${ }^{3,4,5}$, Wei Hu ${ }^{3,4,5}$, Zhou Xiao-Nong ${ }^{3,4,5}$ \\ ${ }^{1}$ Department Biochemistry and Pharmaceutical Sciences, Higher Institute for Health Sciences, Université des \\ Montagnes, Bangangté, Cameroon \\ ${ }^{2}$ Africa Disease Intelligence and Surveillance, Communication and Response (Africa DISCoR) Foundation, Yaoundé, \\ Cameroon \\ ${ }^{3}$ Department of Schistosomiasis Control, National Institute of Parasitic Diseases, China CDC, Shanghai, P.R. China \\ ${ }^{4}$ National Institute of Parasitic Diseases, Chinese Center for Diseases Control and Prevention, P.R. China \\ ${ }^{5}$ WHO Collaborating Center for Tropical Disease Research, Shanghai, P.R. China
}

\begin{abstract}
Objective: Evidence-based and innovative approaches aiming to reduce or eliminate the local and global burden of schistosomiasis are urgently needed. Local elimination has proved difficult and requires vigorous political and financial commitment for prolonged long-term benefits. Yet, available literature provides limited evidence on the impact and effectiveness of different local and national schistosomiasis programs and community interventions models. Integrated schistosomiasis control interventions models in P.R. China have provided hopes that elimination can be achievable goal both endemic areas in China and African countries, where most vulnerable children population lives.
\end{abstract}

Methods: The paper overviewed to what extent and impact of various implemented models and programs, and provides an understanding of the robustness of schistosomiasis control towards elimination interventions in endemic communities in P.R. China and African countries.

Results: It provides vital evidence to galvanize governments and global stakeholders in upholding cost-effective interventions models and research innovations in guiding sustainable decision-making policies and priorities towards achieving global schistosomiasis elimination in China and Africa.

Conclusion: Successful Chinese lessons learnt and experiences from varied schistosomiasis models integration and policies practice holds immense promise when transfer and apply within an integrated trans-disciplinary and intersectorial sectors schistosomiasis approaches in ending schistosomiasis endemicity and epidemics episodes in both P.R. China and African countries. Furthermore ensuring community engagement and participation, health education and resilience towards community projects ownership are essential in sustained national schistosomiasis elimination programmes and eventual eradication benefits. J Microbiol Infect Dis 2017; 7(2): 104-118

Keywords: Schistosomiasis, Intervention, Impact, Control, Elimination, China, Africa

\section{INTRODUCTION}

Moving forward schistosomiasis control towards sustained elimination requires novel surveillance-response implementation in mapping risk factors, reservoir and of endemicity or emerging epidemics resurgence hotspots and evidence-based strategic health programming and financing worldwide [1]. Such surveillanceresponse and monitoring approaches are crucial in assessing the uptake and effectiveness of contextual programs, identifying the strengths and weaknesses and promoting ownership through alignment with national health priorities $[1,2]$. Schistosomiasis or bilharziasis is one of infectious disease of poverty, characterized by severe morbidity and disability that worsens poverty and inequity in vulnerable children in remote settings and resource-limited minority population [2]. Schistosomiasis urogenital and intestinal are responsible the major public health burden and caused by Schistosoma haematobium and $S$. mansoni versus $S$. 
japonicum and $S$. mekongi and snail as the intermediate host in Africa and P.R. China respectively. It is more prevalent in sub-tropical and tropical zones where access and availability to clean water and adequate hygiene is very limited $[1,3,4]$. S. haematobium and $S$. mansoni are found widespread in most endemic countries in Africa, leading to the persistent prevalence of the two common forms of urinogenital and intestinal schistosomiasis[5,6], while $S$. japonicum and $S$. mekongi are mainly intestinal forms in South-East China [5].

In recent times, resurgence in some parts of South-East China and Africa are indications that the disease continues to evolve (natural or manmade evolution) and increase the public health significance in terms of the burden on children and economic cost of any local community and nationwide control programs in most developing countries [6,7]. Estimated 200 million cases of 600 million people at high risk of schistosoma species in 76 countries, it is a significant public health problem, concentrated in sub-Saharan Africa, South East Asia and South America according to World Health Organization [1,3,7]. Repeated and periodic mass chemotherapy administration of antihelmenthic drugs mainly Praziquantel (PZQ) has been the backbone in most national and global schistosomiasis prevention and control programs that have averted millions of deaths in risk and affected populations in these endemic settings[1,3]. For example in 1987, the first systematic mapping that resulted in the global distribution of schistosomiasis Atlas underscored the urgent need for more effective, contextual and inexpensive epidemiological surveillance evaluation in identifying mass chemotherapy in high-risk communities [7-9]. Schistosomiasis distribution is greatly influenced by geographical heterogeneity, adaptation to ecological zonations and evolution requiring an urgent need for accurate disease mapping up the transmission environment and prevalence for appropriate and better public health interventions in P.R. China and African endemic countries $[1,7,9]$.

During the last two decades, substantial achievements and progress have been documented through the implementation of varied top-down or bottom-up interventions models in national schistosomiasis control in
P.R. China and Africa [1,3,5,8]. However existing national control models and strategies may not eliminate the diseases except if innovative, concerted and programmatic strategies developed and used at the same level of intensity at all levels $[10,11]$. So far, limited efforts have been devoted into comprehensive and coherent national and regional sustained control and elimination approach implementation in most endemic African countries [10,11]. Whereas P.R. China national integrated schistosomiasis control strategic in 2004-2008 and 2009-2015 resulted in the interruption of $S$. japonicum transmission. Most recent cases of resurgence occurred in concentrated marshland and lakes regions in Hunan, Hubei, Jiangxi and Anhui provinces and likewise in endemic remote semi-urban and rural settings in Africa $[3,7,12,13]$.

With appropriate and increased political commitment and investment, the strategic China national schistosomiasis elimination strategy has be launched with major goal of elimination of the diseases from 2016-2025 aiming at establishing reliable and operational approaches at interrupting transmission in more than $90 \%$ and elimination in $75 \%$ and $90 \%$ of the endemic counties by 2020 and 2025 respectively [2,3]. Hence, achieving the vision and goal set of China nationwide schistosomiasis free beyond 2025 requires scale up of innovative and integrated functional surveillance-response system interventions. Also, enhanced multisectorial partnership leadership and participation is crucial for sustained funding in strengthening targeted school/faith or community-based mass praziquantel administration (MPA) and improved water, sanitation and hygiene (WASH) programs effectiveness and outcomes. Likewise, leveraging on technological advances in remote sensing mapping and prediction on schistosomiasis prevalence and intensity capacity is needed to support targeted interventions such as environmental snail control strategy through the use of molluscicide and other innovative delivery models, monitoring and evaluation in schistosomiasis elimination in China and Africa.

Likewise in endemic settings in Africa, guiding principles in ensuring the realization and attainment of local settings sustained control into elimination requires government leadership, 
inter-sectorial and multidisciplinary collaboration, increasing community awareness and health education is local to national schistosomiasis control and elimination tactics [3,5,6,8]. Nurturing local/national and regional ownership model for impact could provide new insights into new potential reservoir surveillance or risk factors models and transmission interruption. Assessing existing schistosomiasis knowledge gaps, strengths and weakness are also vital in designing and revamping innovative contextual local schistosomiasis elimination programming and actions plans both P.R. china and Africa [1$3,12,13]$.

This study aimed at evaluating the trend in the impact and effectiveness of different local to national program and intervention delivery models against schistosomiasis control in fostering contextual and integrated schistosomiasis capacity and resilience strategies in elimination agenda in P. R. China and Africa.

\section{METHODS}

\section{Systematic search strategy}

A systematic search of literature was performed in NCBI PubMed, national schistosomiasis survey data, peer-reviewed publications on schistosomiasis control in P.R. China and Africa, and country schistosomiasis surveillance reports, Demographic and Health Surveys (DHS), gntd.org, thiswormyworld.org,map.ox.ac.uk and globalntddatabase.org websites and the Chinese archives for research articles [13,14]. $\mathrm{MesH}$ terms used included 'schistosomiasis control models or strategy, 'schistosomiasis prevalence', MDA or 'anti-schistosomiasis (e.g.: Praziquantel, Albendazile, Niclosamide) as a major subject during the last three decades were assessed for available schistosomiasis prevalence, national schistosomiasis control or elimination models and impacts, communitybased or targeted vulnerable community and population mass praziquantel or fixed praziquantel plus albendazole administration coverage. These terms were used in different types of national policy, programs and mass chemotherapy interventions on schistosomiasis public health burden.

\section{Evaluation and impact evaluation}

A rigorous and quantitative evaluation of model impact process was performed to understand schistosomiasis policy or other intervention model implemented performance and effectiveness, what effects it had, for whom (risk group), how and why. Whereas impact evaluation was specific type of evaluation structured or designed to answer the question of whether the outcomes observed were the result of the intervention or whether the observed outcomes would have happened anyway. Quantitative measurable outcomes such as morbidity and mortality amongst the most vulnerable groups attributable to effective single or combination schistosomiasis programs and interventions applications from 1980 to 2015 or over 35 years period $[14,15]$.

\section{Inclusion criteria}

Inclusion criteria in the study were: 1) schistosomiasis previous and current locations and treatment policy based on time and space; 2) trend in epidemiology in endemic settings African countries and China, 3) studies with all national programs and interventions; 4) molluscicidal in snail control and 5) clear methods and publication in English, French or Chinese languages were included, where reported findings were relevant including reports and publications on theoretical modeling. The review excluded opinion pieces.

\section{Schistosomiasis models of studies}

Models of studies included were classified into intervention, operational, translation, observational, social and ecological. Most communities' social, ecological and interventionbased studies were pre-/post-intervention studies on single and/ or integrated local or national control policy, programs and activities.

\section{Data analysis}

Analysis of selected peer-reviewed, national and regional reports was done using SPSS 13.0 version. All full papers analyzed $(\mathrm{N}=102)$ including personal contact with key schistosomiasis experts both in P.R. China and Africa, summarizing the findings of the data extracted from each study, and exploring the relationships between the results of the different studies. Also, we compared implemented local or national schistosomiasis control and management programs and interventions that 
occurred over time in both Africa and P.R. China. (Figure 1).

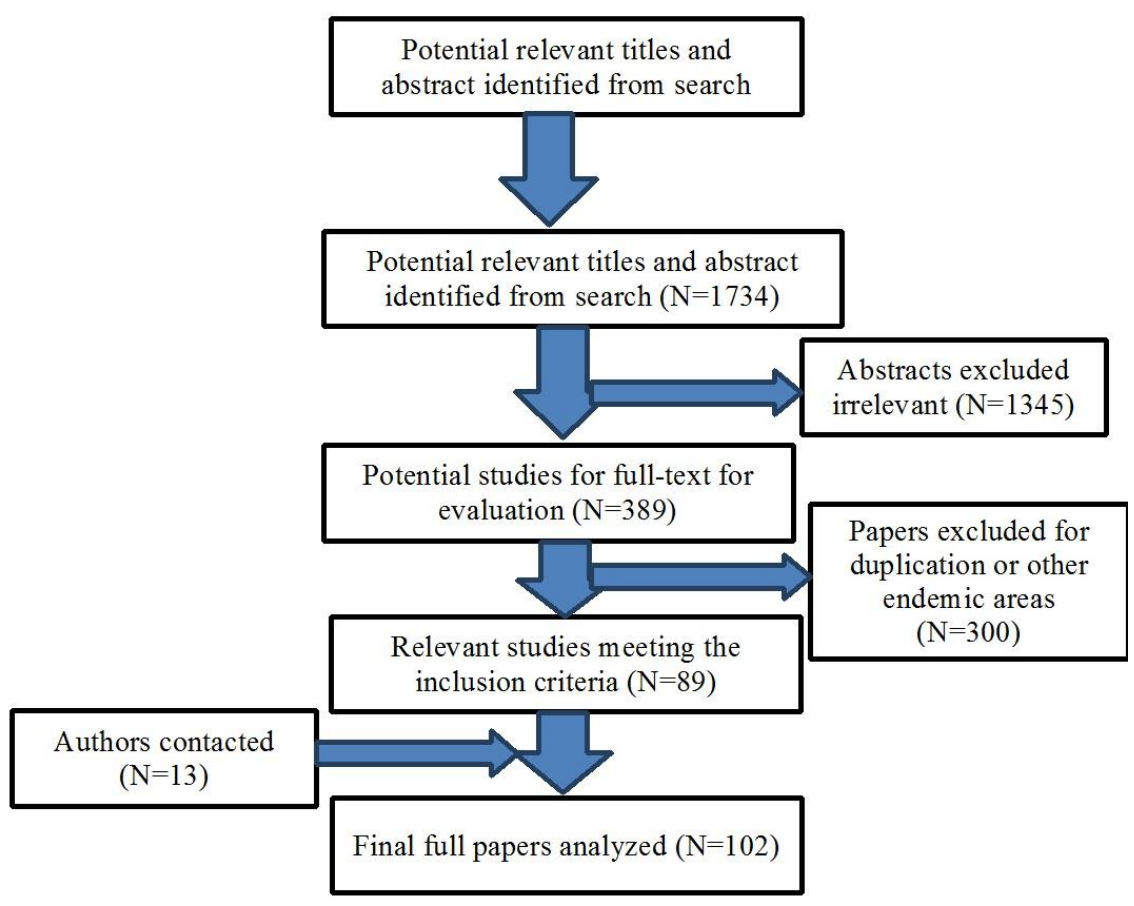

Figure 1: Systematic search approach in intervention models in schistosomiasis control into elimination from 19802015 in P.R. China and African countries.

\section{RESULTS}

\section{Trend in comprehensive schistosomiasis control and elimination programs milestones}

Trend in schistosomiasis public health burden in P.R. China showed that the mid 1950s, schistosomiasis endemicity was reported in 4,078 townships in 12 provinces with a prevalence rate ranging $10,5-11,8$ million in $P$. R. China. China National schistosomiasis control program was inaugurated in 1955, with the discovery of praziquantel, and use for mass chemotherapy, several field studies were conducted in the 80 s supported by the National schistosomiasis research committee with focused on mollisciding, integrated with other measures leading to prevalence reduction of $83 \%$ and $82 \%$ in human and bovines reservoir respectively. From the mid-1950s to 1980 s, emphasis was laid on the control of the intermediate host to interrupt transmission mainly through agricultural modernization and environmental management and used of molluscicide in snail control. In endemic settings in Africa, schistosomiasis is the major neglected tropical diseases (NTDs) that affects and impairs physical and cognitive development and contributes to vulnerable children populations' illness and death. It is one of major cause of poor children educational performance, renders farming or earning a living difficult to children, farmers and fishermen and limits productivity in the workplace as well as drains local and national economic. In most endemic African countries, the national schistosomiasis control programs have led to considerable reduction in the prevalence and mortality rate, but achieving elimination and eventual eradication require contextual mapping in guiding effective and evidence long-term solutions. Fostering community-based ownership of programs and local activities innovations is paramount to sustain active community engagement and resilience in ending schistosomiasis. In such, countries like Tanzania, Sudan, Burundi, Cameroon, Sudan, DRC, Rwanda, Mali, Niger, Eritrea, Senegal, Burkina Faso, Somalia, Zambia and equatorial Guinea showed mixed and scanty longitudinal results and progress sustained to reduce schistosomiasis burden and avert persistent outbreak resurgence costs (Table 1). 
Comprehensive schistosomiasis control and elimination programs milestones were achieved in four out of twelve endemic provinces in P.R. China. Endemic regions mainly in the middle and low Yangtze River, marshals or mountainous regions in Sichuan and Yunnan provinces were then constrained, as achieving sustainable control is very difficult. Importantly, despite the existing drawbacks and challenges, the advent of praziquantel discovery and costeffecetiveness mass drug administration implementation significant encouraged WHOAFRO schistosomiasis network establishment in providing technical assistance and support into incorporation and adaptation of innovative multifaceted sustainable national schistosomiasis strategy over space and time in endemic African countries. For example in P.R. China, the global schistosomiasis control plan shift in 1986, a new evidence-based policy strategy was reformulated based on prompt prevention and treatment, comprehensive integrated measures based on local and seasonal conditions and integration of scientific techniques with mass movement. The resulting policy led to Shanghai, Fujian and Guangdong Schistosomiasis free at end 1986. The 10 years (1992-2001) World Bank loan project on selective mass praziquantel chemotherapy scaling up for impact against schistosomiasis morbidity and mortality was significant in reducing $S$. japonicum infestation intensities and transmission dynamics in humans.19,20,21 Contemporary, present, praziquantel still remain the drug of choice in National Schistosomiasis Control Program in most endemic countries. Recent mass screening of $S$. japonicum P.R. China compared to $S$. haematobium in endemic Africa countries shared that school children are the most vulnerable groups with varied sensitivity and specificity due to socioeconomic status, variability in climatic and geospatial landscape and distribution of China mainland and Africa tropical zones, continuous exposure to poor drinking water, poor hygiene and environment exposure. Some African countries harboured a predominant $S$. haematobium such as Uganda, Ethiopia, Zambia, Tanzania, while other have mixed $S$. haematobium and $S$. mansoni (Cameroon, Burundi, Zambia, Senegal, etc.). Co-infection between schistosomiasis and other infectious disease of poverty are common in most vulnerable groups.
Noteworthy, early warning and surveillance is key factor for effective and targeted response to the persistent trend in schistosomiasis endemicity or epidemics. However, diagnostic challenges in local health centers and national public laboratory in African countries still an unmet need and require urgent attention in sustained control and moving forward into elimination strategies.

\section{Improving detection and diagnosis schistosomiasis control to elimination}

Continuous robust achievements, lessons learnt and experiences in national programs implementation in P.R. China in from 12 endemic provinces with an estimate of 100 million at risk and 11.2 million infected in $21^{\text {st }}$ century was significantly in decreasing the intensity and prevalence of schistosomiasis and moving forward elimination agenda by 2020 . The different in endemicity and case of epidemics in these regions demand novel sensitive and cost-effective diagnostics for accurate identification and timely interventions. Yet, endemic Africa countries still lack more proactive, effective and programmatic approaches in tackling the rampant infestation in its citizenry in most remote rural settings.

Amidst diagnostic methods in isolation and characterization, Kato-katz methods and sedimentation and filtration are used smear eggs counts per gram of feces from infected patient are the most common deployed in Africa in defining the intestinal schistosomiasis intensity categorized according to WHO sensitivity and specificity in the diagnosis guidelines. In addition, microhematuria in urine is the most common proxy-diagnostics marker in urinary schistosomiasis caused by $S$. haematobium. Other direct parasitological examinations still widely used in schistosomes infections including miracidium hatching test (MHT). For example in endemic Zhuxi and Zhonjiang villages in China, the hatching method was more positive cases than the Kato-Katz test did. Historically, indirect immunological assays withS. japonicum infection sensitivity and specificity including antibodies specific detection, indirect hemagglutination assay (IHA) precipitin test (COPT) and Enzyme-linked immunosorbent assay (ELISA) are the most widely used immunodiagnostic tests in China, 
compared to kato-Katz test wider use in African countries. Schistosomiasis elimination requires more sensitive and accurate diagnostics, contextual community-based, field adaptable or household-based in reducing and monitoring emergence or recrudescence as well as intermediate host transmission dynamics interruption strategies.

\section{Impact evaluation of schistosomiasis control models and strategies}

The successes and achievements recorded in national schistosomiasis models rely on varied contextual, effective, reliable and practical Chinese health policy reforms, schistosomiasis multidisciplinary and inter-sectorial platforms. In contrast, methods being deployed in local, national and regional schistosomiasis control in Africa were adapted from global schistosomiasis strategy and remain challenged by complex poverty and inequity vicious cycle, environmental and behavioral factors, geographical and socioeconomic situations. Larval and reservoir sources management using larvicides were successfully implemented in the primary control of cercarae P.R. China and could be deployed in some settings in endemic African countries. Few endemic African countries (e.g. Tanzania, Cameroon, South Sudan, Niger, Chad, Angola, Mozambique, DR Congo and Madagascar) showed little progress national schistosomiasis control whereas three others (e.g.: Nigeria, Burkina Faso and Zimbabwe indicated increasing in infestations and improved funding in schistosomiasis and WASH programs scaling up for impact through mass praziquantel administration coupled with intense community awareness, health education and agricultural improvements, clean drinkable water, sanitation and hygiene can revamp the stagnation (Table 2).

Moreover, larval, adults worms population control and environmental management were also effective strategies to limit favorable breeding sites, the magnitude of infestations using short and long-term programmatic control plans. In 2015, based on comprehensive understanding of the social, ecological, cultural, population behavioral and economic dynamics, evidence-based policy decisions and innovative strategies have been developed in leading China national strategic schistosomiasis elimination agenda by 2020 by experts from National Institute of Parasitic Diseases (NIPD), WHO Collaborating Centre in Tropical Disease Research, Shanghai, China. Achieving this robust agenda for ending schistosomiasis burden requires more effective and contextspecific targets on specific snail control and health education, seasonal variation spatiotemporal mapping in different locality supported by long-term commitment and investment through the global schistosomiasis elimination partnership in leading, providing and monitoring of local/regional integrated schistosomiasis surveillance-response elimination framework, proven models and actions plans implementation.

Importantly, effective monitoring and evaluating of national programs performance and effectiveness successes or limitations in different interventions are essential in understanding knowledge gaps and in generating the evidence-base needed to guide control towards elimination interventions within an integrated context in certain African countries future opportunities and benefits of sustained control and elimination. Still, environmental management would require government commitment to infrastructural management; snail and schistosome population genetic understanding over time. But flexible approach implementation is needed in order to handle local logistics and technical challenges in resource-limited African countries. Combined technological advancement and innovative bioand eco-suitable alternatives or slow-release formulations agents and personal hygiene is essential disinfectants or detergents in hotspots endemic settings.

\section{Strengthening health education, environmental management and improved human sanitation}

Despite the public health impact of schistosomiasis in China and African endemic countries, the low political commitment and level of funding in sustained control and elimination still represents a major setback in upholding the hard won gains and achievements in schistosomiasis control into elimination phases. Continuous community health education, awareness outreach and population social mobilization and engagement are needed in 
strengthening community resilience and participation in sustained schistosomiasis control and elimination activities.

Promoting Africa-China health development in neglected diseases of poverty elimination provides immense opportunities in targeting the uptake and effectiveness enhancements of proven technology, policy reforms and strategies, and exchanges. Improved Table 1. Impact of intervention models on schistosomiasis control and elimination in P.R. China and Africa.

\begin{tabular}{|c|c|c|c|}
\hline Subtype model & Strengths & Weaknesses & Impact \\
\hline Snail control $[21,22]$ & $\begin{array}{l}\text { Can eliminate } \\
\text { sources of snails }\end{array}$ & $\begin{array}{l}\text { There is need to develop a cheap and } \\
\text { effective larvicidal or moluscicidal are } \\
\text { expensive and limited in availability }\end{array}$ & $\begin{array}{l}\text { Cercarae and } S . J \text { was eliminated in } \\
\text { some parts of China and larviciding }\end{array}$ \\
\hline $\begin{array}{l}\text { Environmental } \\
\text { Management and } \\
\text { Personal Hygiene [16] }\end{array}$ & $\begin{array}{l}\text { Can lead to snail } \\
\text { elimination }\end{array}$ & $\begin{array}{l}\text { Environmental modification is } \\
\text { expensive and may be possible only in } \\
\text { more advanced economies }\end{array}$ & Potential to bring about elimination \\
\hline $\begin{array}{l}\text { Immunization of Animals } \\
\text { [20] }\end{array}$ & $\begin{array}{l}\text { Cost-effective and } \\
\text { simple to } \\
\text { implement }\end{array}$ & $\begin{array}{l}\text { Only effective for controlling the } \\
\text { animals dynamics }\end{array}$ & $\begin{array}{l}\text { It may fail as it does not target seasonal } \\
\text { mobile animals feeding, which are } \\
\text { responsible for the transmission }\end{array}$ \\
\hline $\begin{array}{l}\text { Health education and } \\
\text { Advocacy }\end{array}$ & $\begin{array}{l}\text { Cost-effective and } \\
\text { simple to } \\
\text { implement }\end{array}$ & $\begin{array}{c}\text { Effective but requires continuous and } \\
\text { sustained efforts }\end{array}$ & Potential to bring aboutelimination \\
\hline Biological control $[16,23]$ & $\begin{array}{l}\text { Effective if } \\
\text { implemented } \\
\text { correctly }\end{array}$ & $\begin{array}{l}\text { Expensive and technically challenging } \\
\text { for poorer countries }\end{array}$ & Potential to bring about snail elimination \\
\hline
\end{tabular}

Table 2. Impact of transmission blocking models in schistosomiasis control and elimination In P.R. China and endemic African countries.

\begin{tabular}{|c|c|c|c|}
\hline Subtype & Strengths & Weaknesses & Impact \\
\hline $\begin{array}{c}\text { Prevention of } \\
\text { Contamination: Public }\end{array}$ & $\begin{array}{l}\text { Effective, cheap and easily } \\
\text { implementable }\end{array}$ & $\begin{array}{l}\text { Only offers individual protection and difficult on } \\
\text { population and time scale }\end{array}$ & $\begin{array}{l}\text { Animals can still transmit } \\
\text { the disease }\end{array}$ \\
\hline $\begin{array}{c}\text { Preventive } \\
\text { chemotherapy: } \\
\text { Transmission blocking }\end{array}$ & $\begin{array}{c}\text { Schistosome and } \\
\text { hepatocytic stages } \\
\text { targeted, could have } \\
\text { simultaneous prevention of } \\
\text { onset of disease } \\
\text { Fast acting, prevents onset } \\
\text { of infection and disease }\end{array}$ & $\begin{array}{l}\text { Drug delivery and technicalconstraints } \\
\text { Resistance emergence }\end{array}$ & $\begin{array}{l}\text { Yes, needed } \\
\text { No, not if only targeting } \\
\text { prevention of infection }\end{array}$ \\
\hline $\begin{array}{l}\text { Awareness, Food } \\
\text { Safety, Education and } \\
\text { Environmental } \\
\text { Management }\end{array}$ & $\begin{array}{l}\text { Safe for humans and } \\
\text { environment, stop } \\
\text { transmission cycle }\end{array}$ & $\begin{array}{l}\text { Chemicals that attract snail have not been } \\
\text { isolated, mechanization, uses of moluscidal, } \\
\text { larvicidal. Cleaning surroundings, hygiene } \\
\text { labour intensive urbanization hazards. User } \\
\text { acceptability may be a challenge }\end{array}$ & $\begin{array}{l}\text { Emerging technology will } \\
\text { eliminate the need to spray } \\
\text { chemicals } \\
\text { Very promising technique } \\
\text { and does not reduce } \\
\text { population exposure, but } \\
\text { worked well for several } \\
\text { China counties }\end{array}$ \\
\hline $\begin{array}{l}\text { Individual } \\
\text { Chemotherapy: } \\
\text { Treatment of disease }\end{array}$ & $\begin{array}{l}\text { Decrease S.japonicum an } \\
\text { and S. mansoni burden, } \\
\text { treat-associated symptoms } \\
\text { Treatment of } S \text {. } \\
\text { hematobium liver stage }\end{array}$ & $\begin{array}{c}\text { Resistance developed, new drugs and targets } \\
\text { needed } \\
\text { Technical constraints in drug development }\end{array}$ & $\begin{array}{l}\text { Maybe, if drugs block liver } \\
\text { development } \\
\text { Maybe, species specific } \\
\text { eliminations }\end{array}$ \\
\hline $\begin{array}{l}\text { Mass Chemotherapy } \\
\text { and Transmission } \\
\text { Blocking Vaccines }\end{array}$ & $\begin{array}{c}\text { Block human-animal } \\
\text { transmission, could have } \\
\text { simultaneous prevention of } \\
\text { onset ofdisease }\end{array}$ & $\begin{array}{c}\text { Technical constraints in drug or vaccines } \\
\text { development }\end{array}$ & Yes, needed \\
\hline
\end{tabular}




\section{DISCUSSION}

Our findings showed that national schistosomiasis in P.R. China, surveillance system including trend in the diagnostic tests impact recorded an overall prevalence of 43.7$82.7 \%$ in Jiangsi, Zhejing, Shanghai, Fujian, Guandong, Yunan, Hunan, Jiangsu, Hubei, Anhui, Guangxi provinces including lakes and regions situated along the southern part between 22.50 and $33.25 \mathrm{NL}$ and Yansze river and its tributaries[1,4,7,15,16]. It is documented that major reservoirs for $S$. japonicum infection in the P.R. China are cattle and water buffaloes) with estimated $75 \%-90 \%$ of egg contamination source $[17,18,19,20]$. Further integrated attention and coordination efforts with veterinary public health and agricultural sectors innovative solutions to stamp out resurgence ad persistent burden on minority and vulnerable populations in most developing countries [21,22,23,24,25]. In addition, risk factors included severe lack of potable and drinkable water, continuous usage and exposure to contagious water exposure, poor sanitation and hygiene, weak knowledge and uneven community awareness and social mobilization on schistosomiasis transmission, early diagnostic and prompt treatment gaps as well as other lack of standard practices in occupational activities need to be addressed [6,15,16,26-29].

We documented that these models approaches varied from snail control, structural, technical and management inefficiencies $[1,3,34,78,99]$, and reservoir control through scaling up programs and interventions namely the use of mollusciding agents, health educational and awareness, and praziquantel targeted/mass administration [4,34,35,38,39]. Moving forward China national strategic schistosomiasis elimination agenda with specific interventions and timelines by 2020 [1,3,4,40-45] Scaling up targeted approaches such as improved hygiene and environmental sanitation deployment, improved public latrines and mechanization coupled with focal risk setting mass chemotherapy in national schistosomiasis elimination implementation countering or resurgence countermeasures across African endemic countries [46-50].

Nowadays, molecular detection are more sensitive, specific and reliable but more expensive using polymerase chain reaction (PCR) based assays in $S$. hematobium, $S$. mansoni, and $S$. japonicum infections from sera, feces, urine and blood [77-81],compared to katoKatz in Africa $[4,9,17,20,44,45]$. Thus, promoting capacity development of local and national health professional through Chinese technology transfer and cross-sectoral collaboration in data sharing between the ministries of health and agriculture is vital to minimize poverty and occupational (e.g. agriculture and fishing)associated schistosomiasis risks in most endemic Africa countries [1,52-56].

Exploitation of school and faith-based schistosomiasis control programs in recent times have showed substantial positive impact on improving children knowledge and behavior changes, enhanced teaching and learning on good practices in smart WASH, sanitation and hygiene, and most importantly social and behavioral changes [1,3,60-64].

It is worth noting that from 2004-2010, the revised national strategies for the treatment and control of schistosomiasis (NSTCS) was effective and successful in interruption of humans and bovines interactions and contamination in moving forward elimination agenda by 2020 [1,3,65,77-79]. The successes of approach in China was coupled with technical support to the local communities health workers, training in diagnostics and case management, safe water supply, reconstruction of latrines and sanitation, mechanization of agriculture practices, heath education and mass chemotherapy $[13,55,63,64,71,80-83]$. Thus, effective and contextual integrated approach to local healthcare workers, technological advancements to support self-learning and information sharing on transmission interruption, active protection and mitigation from environmental risk and compliance to mass drug administration [23,35,82-87]. Enhanced ChinaAfrica health development technology transfer, capacity building and institutional collaborative exchanges on operational research and development is crucial in ending schistosomiasis revamping regionally and globally $[88,89,90]$.

Evidence derived from various studies both in China and Africa endemic settings have shown that implementation of animal sustainable animals immunization and establishing human 
mass drug administration in hotspots epidemics areas, improved agricultural and environmental changes mitigation and adaptation are of importance to interrupt schistosomiasis virulence and transmission dynamics [91,92]. Designing effective and reliable immunization policies and programs to local settings in partnership and collaboration with local community are essential in identifying potential treat or resurgence and in providing information for adaptation of integrated tailored interventions [93,94].

Further research are needed in developing vaccination can also target schistosomulum for protective immune response or buffaloes or cattle blocking parasite fecundity safe vaccines and novel drugs and vaccines development are much needed. Optimizing schistosomiasis sustained control and elimination strategies in prevention of reintroduction in previous settings where transmission interruption and snail control have been successful in PR China and should be upheld toward eventual eradication. Recently, artemisinins derivatives have been found effective in the treatment of schistosomiasis but the increasing emergence and spread of resistance present challenging steps[1,5], and the urgent need to pay focus on development of novel agents targeting novel targets vaccine and proven efficient tactics in sustained schistosomiasis control into elimination strategies (Table 1\&2).

Schistosomiasis preventive mass chemotherapy has been achieved through drugs mainly praziquantel threshold and regimens implementation in seasonal prophylactic interventions, while active community education, mobilization and participatory resilience in schistosomiasis risk factors mitigations and adaptations $[3,4,84]$. This strategy has not only reduced morbidity and mortality, but it uses of mass drug administration in schistosomiasis, food-borne trematodes and helminthiasis showed laudable benefits. Such preventive approach benefits include increasing school attendance and children development, community social cohesion and increasing in household farmers and fishermen income, remote rural or forest fridges and informal living areas [95,96]. Other advantages include community compliance within health-care programmes, increasing school attendance and value-added performance. Sustainable evidence-based community programs and projects establishment in accelerating schistosomiasis, helminthes and food-borne infections control and eventual elimination.[90,97]. Previous reports have indicated mass drug administration from country/county endemic settings including the use of praziquantel (PZQ), ivermectin, albendazole or mebendazole drugs proven safe and effective in large scale deployment in different regimen depending on the target population $[2,3,34]$.

Until now local and regional schistosomiasis targeted population mass chemotherapy control in Africa countries still relies on mass PZQ for prophylactic and chemotherapy. The absence of safe and effective vaccine and PZQ alternatives represents a major setback in sustained control and moving forward into elimination phases $[2,3,15,16]$. However, the remerging situation of schistosomiasis in previously eliminated zones signals that the battle is not yet over. Innovative formulations and long-lasting practical strategies that are enshrined in cultural and behavior mitigation and adaptation models of vulnerable children and communities require urgent attention in ending schistosomiasis burden. Increasing resurgence of both snail abundance and disease prevalence have been linked to some factors including climate changes associated floods, social and ecological, and poverty related factors $[2,7,8,92.96]$. Sustainable funding from government and private stakeholders including communities engagement and participation is imperative to establish proven and effective interventions and measures uptake and adherence in sustained control and elimination stages of $S$. japonicum or $S$. haematobium and $S$. mansoni species $[1,2,15,16]$. As current schistosomiasis control programs using $P Z Q$ alone are threatened by climate changes and environmental hazards that progressive induced the development of drugand larvicidal-resistant forms and improving ecosystem improvements [1,3,15,16,85-87,90].

Animal immunization programs have been effective targeting of the prevention of disease transmission in some parts of China but in Africa its replication might be partial or require systematic adaptation based on contextual realities as seasonal migration due to unavailability of feeding for the animals still 
represents bottlenecks in control of transmission between humans and snail intermediate host (Table 2) $[3,77,93,97]$. An integrated and evidence-based approach and shared responsibility requires in assessing the standards and performance indicators, in monitoring and evaluation (M\&E) of schistosomiasis control and elimination activities. Such strategic M\&E tasks are to draw and recommend short and long-term according to the geographical mapping and distribution of the reservoir and disease burden [2,3].

Implementation of contextual comprehensive and sustainable interventions relies on the community-based uptake approaches from snail infested grasslands removal, providing mechanization of farming and irrigation practices. Sustainability of local strategies towards interrupting schistosomiasis transmission elimination also requires improving sanitation by supplying clean drinking water and improving WASH approach in remote rural communities/ dwellings including intensive health education a continuous awareness and resilience [2,15,29,93-95]. Moreover, to nurture schistosomiasis ownership and reinforcement of public-private partnership and collaboration including the local community in sustained funding support from government and international organizations and development of disease resilience culture are proactive and efficient ways in revamping the persistent morbidity and mortality of this diseases China and mainly in sub-Saharan Africa $[3,5,19,96,99$ 102].

The paper reviews limitations included limited local peer reviewed data or publications from some high endemic areas in African countries compared to P. R. China, different national control programs and methodologies in reviewed studies, and different data sets and sparse and incoherent information in some endemic Africa countries.

\section{Conclusion}

The review provides evidence-based approaches to facilitate the implementation of sustainable control interventions towards elimination of schistosomiasis and other emerging infectious diseases of poverty. Also, novel integrated surveillance-response systems implementation for early and rapid detection assessment of threat or outbreak can enhance cost-effectiveness management and national schistosomiasis priorities. Contemporary genomic data mining in forecasting and modeling provide new opportunities in unraveling new point of care and reliable diagnostics, safe and efficacious drug and vaccine in schistosomiasis elimination [99,101, 102,103]. Moreover understanding climatic and environmental interactions and impact is needed. Schistosomiasis control towards elimination strategies are highly reliant on transdisciplinary approaches, as depicted by integrated human-animal-environment approaches including: 1) Integrated intersectorial and multi-sectorial operational approaches are needed in accelerating contextual evidence-based decision-making priorities, innovative social mobilization and community participatory engagement and resilience; 2) Implementation of surveillanceresponse in strengthening local and migrants including fishermen and nomadic cattle monitoring and tracking, 3)Intensification of snail geospatial epidemiologic distribution and molecular clues in local and national schistosomiasis programs, 3) Embarking of strategic Chinese experiences, capacity transfer and lessons learnt in successful schistosomiasis control towards elimination to other endemic countries such as Africa, 4) Establishing of population-based database mainly in vulnerable school or faith-based and preschool children in understanding the economic, social and ecological, cultural and environmental determinants and impact on the persistent disease burden; 5) Strengthening more sensitive public health laboratory capacity and effectiveness through application of cutting-edge standardization methods in effective national schistosomiasis surveillance in prevention, control and elimination programs; 6) Strengthening monitoring and evaluation of programs quality and effectiveness based on seasonal variations and transmission dynamics or epidemics occurrences; 7) Prioritizing the development and applications of multicomponent integrated elimination approaches and strategies including animal-human vaccination delivery in achieving the national and regional "One Health" approach and workforce impact in ending local and global neglected infectious diseases of poverty. 


\section{Author contribution}

ET conceived the study and designed the framework. . ET and TX reviewed the papers on schistosomiasis studies and drafted the manuscript. ET, JTW, NX, HW and ZXN critical reviewed and improved on the manuscript. ET critically revised the manuscript. All authors read and approved the final version of the manuscript.

\section{Acknowledgements}

We are grateful to http://www.thiswormyworld.org/maps and http://whqlibdoc.who.int/publications/2006/92415 47103_eng.pdf for all additional information on Schistosomiasis.

Conflict of interest: The authors declare that they have no competing interests.

\section{REFERENCES}

1. World Health Organization. First WHO report on neglected tropical diseases: working to overcome the global impact of neglected tropical diseases. Geneva: WHO Press; 2010.

2. World Health Organization (WHO), 2015 Schistosomiasis: Key facts. http://www.who.int/mediacentre/factsheets/fs115/e $\mathrm{n} /$ accessed, $15^{\text {th }}$ December 2015

3. Xu J, Bergquist R, Qian YJ, et al. China-Africa and China-Asia Collaboration on Schistosomiasis Control: A SWOT Analysis. Adv Parasitol 2016; 92:435-66.

4. Tambo E, Khater El, Chen JH, Bergquist R, Zhou $\mathrm{XN}$. Nobel prize for the artemisinin and ivermectin discoveries: a great boost towards elimination of the global infectious diseases of poverty. Infect Dis Poverty 2015; 28;4:58.

5. Collins C, Xu J, Tang S: Schistosomiasis control and the health system in China. Inf Dis Poverty 2012, 1 (1):7.

6. Bergquist $R$, Tanner M: Controlling schistosomiasis in South-East Asia: a tale of two countries. Adv Parasitol 2010, 72:109-144.

7. WHO: Accelerating work to overcome the global impact of neglected tropical diseases-a roadmap for implementation. Geneva: WHO Press; 2012.

8. Savioli L, Fenwick A, Rollinson D, Albonico M, Ame SM. An achievable goal: control and elimination of schistosomiasis. Lancet 2015 22; 386 (9995):739.

9. Krauth SJ, Greter H, Stete K, et al. All that is blood is not schistosomiasis: experiences with reagent strip testing for urogenital schistosomiasis with special consideration to very-low prevalence settings. Parasit Vectors 2015; 8:584.

10. Anderson R, Hollingsworth TD, Truscott J, Brooker S: Optimisation of mass chemotherapy to control soil-transmitted helminth infection. Lancet 2012, 379 (9813):289-290.

11. Sacko M, Magnussen $P$, Keita AD, Traore MS, Landoure A, et al. Impact of Schistosoma haematobium infection on urinary tract pathology, nutritional status and anaemia in school-aged children in two different endemic areas of the Niger River Basin, Mali. Acta Trop 2011; 120 Suppl 1:S142-50

12. Bergquist $R$, Whittaker $M$ : Strengthening control of neglected tropical diseases in the Asia Pacific region: implications for health information priorities. Inf Dis Poverty 2012, 1(1):4.

13. Chitsulo L, Engels D, Montresor A, Savioli L. The global status of schistosomiasis and its control. Acta Tropica 2000; 77:41-51.

14. Utzinger $J$, Bergquist $R$, Olveda $R$, Zhou XN: Important helminth infections in South-East Asia diversity, potential for control and prospects for elimination. Adv Parasitol 2010, 72:1-30.

15. Brooker S, Hotez PJ, Bundy DAP: The global atlas of helminth infection: mapping the way forward in neglected tropical disease control. PloS Negl Trop Dis 2010, 4:e779.

16. Donald P. McManus and Alex Loukas: Current Status of Vaccines for Schistosomiasis. Clin Microbiol Rev 2008, 21 (1):225.

17. Doumenge JP et al. Atlas of the global distribution of schistosomiasis. Geneva: World Health Organization; 1987.

18. Hotez PJ, Ehrenberg JP: Escalating the global fight against neglected tropical diseases through interventions in the Asia Pacific region. Adv Parasitol 2010, 72:31-53.

19. Bergquist R, Utzinger J, McManus DP Trick or treat: the role of vaccine in integrated schistosomiasis control. PLoS Negl Trop Dis 2008; 2: e244. doi:10.1371/journal.pntd.0000244

20. Mo AX, Colley DG. Workshop report: Schistosomiasis vaccine clinical development and product characteristics. Vaccine 2015 Dec 22. pii: S0264-410X(15)01823-X.

21. Driguez P, McManus DP, Gobert GN. Clinical implications of recent findings in schistosome proteomics. Expert Rev Proteomics 2016; 13(1):19-33.

22. Gurarie D, Yoon N, Li E, et al. Modelling control of Schistosoma haematobium infection: predictions of the long-term impact of mass drug administration in Africa. Parasit Vectors 2015 22;8:529. 
23. Da'Dara AA, Li YS, Xiong T, et al. DNA-based vaccine protects against zoonotic schistosomiasis in water buffalo. Vaccine 2008; 26: 3617-3625

24. Williams GM, Sleigh AC, Li YS, et al. Mathematical modelling of schistosomiasis japonica: comparison of control strategies in the Peoples' Republic of China. Acta Trop 2002; 82: 253-262.

25. Wang LD, Chen HG, Guo, JG, et al. A strategy to control transmission of Schistosoma japonicum in China. N Eng J Med 2009; 360: 121-128

26. Liu ZC, He HB, Wang ZX, et al. Effect of marshland isolation and grazing prohibition on schistosomiasis control in Dongting Lake region [in Chinese]. Chin J Schisto Control 2010; 22: 459-463.

27. Zeng QR, Hou JW, He YK, et al. Analyses on morbidity and chemotherapy effects of Schistosoma japonicum infection in fishermen on Dongting Lake. Chin J Parasitol Parasit Dis 2004; 22:199-203

28. Zhou J, Huang CY, He YK, et al. Epidemiological evaluation of schistosomiasis in migrant fishermen in Dongting Lake region. Chin J Schisto Control 2010; 22: 464-467.

29. McCreesh N, Nikulin G, Booth M. Predicting the effects of climate change on Schistosoma mansoni transmission in eastern Africa. Parasit Vectors. 2015; 8:4.

30. Xu J, Yu Q, Tchuenté LA, et al. Enhancing collaboration between China and African countries for schistosomiasis control. Lancet Infect Dis 2016; 16 (3):376-83.

31. Stothard JR, Campbell SJ, Osei-Atweneboana MY, et al. Towards interruption of schistosomiasis transmission in sub-Saharan Africa: developing an appropriate environmental surveillance framework to guide and to support 'end game' interventions. Infect Dis Poverty 2017; 6 (1):10.

32. Hürlimann E, Schur N, Boutsika K, et al. Toward an open-access global database for mapping, control, and surveillance of neglected tropical diseases. PLoS Negl Trop Dis 2011, 5(12):e1404.

33. Clements ACA, Firth $S$, Dembelé $R$, et al. Use of Bayesian geostatistical prediction to estimate local variations in Schistosoma haematobium infection in western Africa. Bull World Health Organ 2009, 87:921-929.

34. Sun LP, Liang YS, Wu HH, et al. A Google Earthbased surveillance system for schistosomiasis japonica implemented in the lower reaches of the Yangtze River, China. Parasit Vectors 2011, 4:223.

35. Fenwick A, Webster JP, Bosque-Oliva E, et al. The Schistosomiasis Control Initiative (SCI): rationale, development and implementation from 2002-2008. Parasitology 2009, 136:1719-1730.

36. McManus DP, Gray DJ, Li YS, et al. Schistosomiasis in the Peoples' Republic of China: the era of the Three Gorges Dam. Clin Microbiol Rev 2010; 23: 442-466.

37. Gray DJ, Williams GM, Li YS, et al. A clusterrandomised intervention trial against $S$. japonicum in the Peoples' Republic of China: bovine and human transmission. PLoS One 2009; 4: e5900.

38. Da'Dara AA, Li YS, Xiong T, Zhou J, et al. DNAbased vaccine protects against zoonotic schistosomiasis in water buffalo. Vaccine 2008; 26: 3617-3625.

39. Tambo E, Ugwu CE, Guan Y, Wei D, Xiao-Ning, Xiao-Nong Z. China-Africa Health Development Initiatives: Benefits and Implications for Shaping Innovative and Evidence-informed National Health Policies and Programs in Sub-saharan African Countries. Int J MCH AIDS 2016; 5 (2):119-133.

40. Katz N, Chavez A, Pellegrino J. A simple device for quantitative stool thicksmear technique in schistosomiasis mansoni. Rev Inst Med Trop Sao Paulo 1972; 14: 397-400.

41. Montresor A, Crompton DWT, Hall A, Bundy DAP, Savioli L. Guidelines for the evaluation of soiltransmitted helminthiasis and schistosomiasis at community level. A guide for managers of control programmes. Geneva: World Health Organization. 1998 pp 1-45.

42. Hou XY, McManus DP, Gray DJ, et al. A randomised, double-blind, placebo-controlled trial on the safety and efficacy of combined praziquantel and artemether treatment for acute Schistosomiasis japonica in China. Bull World HIth Org 200886: 788-795.

43. Yuan LP, Manderson L, Tempongko MS, Wei W, Aiguo $P$. The impact of educational videotapes on water contact behaviour of primary school students in the Dongting Lakes region, China. Trop Med Int Health 2000; 5: 538-544.

44. Dessein A, Chevillard C, Arnaud V, et al. Variants of CTGF are associated with hepatic fibrosis in Chinese, Sudanese and Brazilians infected with schistosomes. J Exp Med 2009; 206: 2321-2328.

45. Massenet D, Toukour A, Kamwa Ngassam RI, Djao R, Portal JL, Tchuem Tchuente LA. Changes in the distribution of human schistosomiasis in far North Province, Cameroon, since 1986. Annals of Trop Medicin Parasit 2011; 105: 325-328

46. Saotoing $P$, Vroumsia T, Njan AM, Tchuenguem FN, Messi J. Epidemiological survey of schistosomiasis due to Schistosoma haematobium in some primary schools in the town of Maroua, far north region Cameroon. International Journal of Tropical Medicine 2011; 6: 19-24 
47. Njiokou F, Yimta Tsemo LC, Kuete T, Same Ekobo A. Dynamics of intestinal schistosomiasis in Cameroon: evolution of transmission in the mixed zone of Nkolmebanga, Lekie. Medecine Tropicale 2004; 64: 351-354

48. Mao CP. A review of the epidemiology of schistosomiasis japonica in China. Am J Trop Med 1948; 28: 659-672.

49. Chen XY, Wang LY, Cai JM, et al. Schistosomiasis control in China: the impact of a 10-year World Bank Loan Project (1992- 2001). Bull World Health Organ 2005; 83: 43-48.

50. Yuan HC, Jiagang $G$, Bergquist $R$, et al. The 1992- 1999 World Bank schistosomiasis research initiative in China: outcome and prospectives. Parasitol Int 2000; 49: 195-207.

51. Li YS, Sleigh AC, Tanner M, et al. Five-year impact of repeated praziquantel chemotherapy on sub-clinical morbidity due to Schistosoma japonicum in China. Trans Roy Soc Trop Med Hyg 2002; 96: 438-443.

52. Ross AG, Sleight AC, Li YS, McManus DP. Schistosomiasis in the People's Republic of China: prospects and challenges for the $21^{\text {st }}$ century. Clin Microbiol Rev 2001; 14: 270-295.

53. Zhou XN, Wang LY, Chen MG, et al. The publichealth significance and control of schistosomiasis in China-then and now. Acta Trop 2005; 96: 97-105.

54. Zhou XN, Gou JG, Wu XH, et al. Epidemiology of schistosomiasis in the People's Republic of China, 2004. Emerg Infect Dis 2007; 13: 1470-1476.

55. Wang LD, Zhou XN. Schistosomiasis control: experience and lessons from China. Lancet 2008; 372: 1793-1795.

56. McManus DP, Li YS, Gary D, Ross AG. Conquering 'snail fever': schistosomiasis and its control in China. Expert Rev Anti Infect Ther 2009; 7: 473-485.

57. McManus DP, Gray D, Li YS, et al. Schistosomiasis in the People's Republic of China: the era of the Three Gorges Dam. Clin Microbiol Rev 2010; 23: 442-466.

58. Li YS, Sleigh AC, Ross AGP, et al. Epidemiology of Schistosoma japonicum in China: morbidity and strategies for control in the Dongting Lake region. Int J Parasitol 2000; 30: 273-281.

59. Li YS, Raso G, Zhao ZY, et al. The impact of large water management projects on schistosomiasis transmission and control in the Dongting Lake region, China. Emerg Infect Dis 2007; 13: 973979.

60. Li YS, Sleigh AC, Ross AGP, et al. Two year impact of praziquantel for Schistosoma japonicum infection in China: re-infection, subclinical disease and fibrosis marker measurements. Trans Roy Soc Trop Med Hyg 2000; 94: 191-197.

61. Sandbach FR. Farewell to the god of plague - the control of schistosomiasis in China. Soc Sci Med 1977; 11: 27-33.

62. Zheng J. Achievements and challenges in schistosomiasis control in China. Zhongguo Ji Sheng Chong Xue Yu Ji Sheng Chong Bing Za Zhi 2009;27: 398-401.

63. Raso G, Li YS, Zhao Z, et al. Spatial distribution of human Schistosoma japonicum infections in the Dongting Lake Region, China. PLoS ONE 2009; 4 : e6947. doi:10.1371/journal.pone.0006947.

64. Johansen MV, Bøgh HO, Nansen P, Christensen NO. Schistosoma japonicum infection in the pig as a model for human schistosomiasis japonica. Acta Trop 2000; 76: 85-99.

65. Gray DJ, Williams GM, Li YS, et al. A cluster randomised intervention trial against Schistosoma japonicum in the Peoples' Republic of China: bovine and human transmission. PLoS One 2009 4: e5900. doi:10.1371/journal.pone.0005900.

66. Joanne P. Webster, Charlotte M. Gower, Alice J. Norton: Evolutionary concepts in predicting and evaluating the impact of mass chemotherapy schistosomiasis control programmes on parasites and their hosts. Evolutionary Applications J 2008 $1(1)$.

67. Yi-biao Zhou, Hui-min Zheng and Qing-wu Jiang: A diagnostic challenge for schistosomiasis japonica in China: consequences on praziquantelbased morbidity control. Parasites \& Vectors 2011, 4:194.

68. Enk MJ, Oliveira e Silva G, Rodrigues NB Diagnostic Accuracy and Applicability of a PCR System for the Detection of Schistosoma mansoni DNA in Human Urine Samples from an Endemic Area. PLoS One 2012; 7(6): e38947.

69. Guo JG, Li YS, Gray DJ, et al. A drug-based intervention study on the importance of buffaloes for human Schistosoma japonicum infection around Poyang Lake, Peoples' Republic of China. Am J Trop Med Hyg 2006; 74: 335-341.

70. Galappaththi-Arachchige HN, Amlie Hegertun IE, Holmen S, et al. Association of Urogenital Symptoms with History of Water Contact in Young Women in Areas Endemic for S. haematobium. A Cross-Sectional Study in Rural South Africa. Int J Environ Res Public Health. 2016;13 (11). pii: E1135.

71. Cai KP, Zuo JZ, He HB, Zhuo SJ. Impact of changes in mud siltation of Dongting Lake on the endemic factors of schistosomiasis after building the Three Gorges Dam. Pract Prevent Med 2000; 7: 1-3. 
72. Zhou XN, Bergquist $\mathrm{R}$, Leonardo $\mathrm{L}$, et al. Schistosomiasis japonica control and research needs. Adv Parasitol 2010; 72: 145-178.

73. Zhu HM, Xiang S, Yang $\mathrm{K}, \mathrm{Wu} X \mathrm{H}$, Zhou XN. Three Gorges Dam and its impact on the potential transmission of schistosomiasis in regions along the Yangtze River. Ecohealth 2008; 5: 137-148.

74. Gryseels B, Polman K, Clerinx J, Kestens L. Human schistosomiasis. Lancet 2006; 368: 11061118.

75. Li YS, Chen D, Ross AG, Zhou J, Burke ML, et al. Severe hepatosplenic schistosomiasis: clinicopathological study of 102 cases undergoing splenectomy. Hum Pathol 2011; 42: 111-119.

76. Dai JR, Wang W, Liang YS, et al. A novel molluscicidal formulation of niclosamide. Parasitol Res 2008; 103: 405-412.

77. Yuan LP, Manderson L, Tempongko MS, Wei W, Aiguo $P$. The impact of educational videotapes on water contact behaviour of primary school students I the Dongting Lakes region, China. Trop Med Int HIth 2000; 5: 538-544.

78. Yuan LP, Manderson L, Ren MY, et al. Schoolbased interventions to enhance knowledge and improve case management on schistosomiasis: a case study from Hunan, China. Acta Trop 2005; 96: 248-254.

79. Kosinski KC, Kulinkina AV, Tybor D, Osabutey D, Bosompem KM, Naumova EN. Agreement among Four Prevalence Metrics for Urogenital Schistosomiasis in the Eastern Region of Ghana. Biomed Res Int 2016; 2016:7627358.

80. Kariuki HC, Ivy JA, Muchiri EM, Sutherland LJ, King $\mathrm{CH}$. Divergent Effects of Schistosoma haematobium Exposure on Intermediate-Host Snail Species Bulinus nasutus and Bulinus globosus from Coastal Kenya. Am J Trop Med Hyg 2017; 96 (4):850-855.

81. Arnaud V, Fu X, Wang Y, et al. Cytokines in severe hepatic central and peripheral fibrosis in humans infected with Schistosoma japonicum: IL10 and IFN-c likely play crucial regulatory roles. $J$ Infect Dis 2008; 198: 418-426.

82. Ross AG, Li YS, Sleigh AC, et al. Epidemiological features of Schistosoma japonicum among fishermen and other occupational groups in the Dongting Lake Region (Hunan Province) of China. Am J Trop Med Hyg 1997; 57: 302-308.

83. Bergquist R, Johansen MV, Utzinger J. Diagnostic dilemmas in helminthology: what tools to use and when? Trends Parasitol 2009; 25: 151-156.

84. Ellis MK, Li YS, Hou XY, Chen HG, McManus DP. STNFR-II and SICAM-1 are associated with acute disease and hepatic inflammation in schistosomiasis japonica. Int $\mathrm{J}$ Parasitol 2008; 38: 717-723.
85. Hou XY, Ellis M, McManus, DP, et al. Diagnostic value of non-invasive biomarkers for stagespecific diagnosis of hepatic fibrosis in patients with advanced schistosomiasis japonica. Int $\mathrm{J}$ Parasitol 2011; 41: 325-332.

86. Bustinduy AL, Friedman JF, Kjetland EF, et al. Expanding Praziquantel (PZQ) Access beyond Mass Drug Administration Programs: Paving a Way Forward for a Pediatric PZQ Formulation for Schistosomiasis. PLoS Negl Trop Dis 2016 22; 10(9):e0004946.

87. Hsiang MS, Carlton EJ, Zhang Y, et al. Use of ultrasonography to evaluate Schistosoma japonicum-related morbidity in children, Sichuan Province, China, 2000-2007. Am J Trop Med Hyg 2010; 82: 103-111.

88. Li YS, Kardorff R, Richter J, et al. Ultrasound organometry: the importance of body-height adjusted normal ranges in assessing liver and spleen parameters among Chinese subjects with Schistosoma japonicum infection. Acta Trop 2004; 92: 133-138.

89. Chiavaroli R, Grima P, Grima P. Detection of early liver fibrosis in patients with intestinal schistosomiasis: sonographic and histologic findings in Schistosoma mansoni infection. Infection 36: 585-589.

90. Okosun KO, Smith R. Optimal control analysis of malaria-schistosomiasis co-infection dynamics. Math Biosci Eng 2017; 14(2):377-405

91. Xiao SH. Development of antischistosomal drugs in China, with particular consideration to praziquantel and the artemisinins. Acta Trop 2005; 96:153-167.

92. Utzinger J, Xiao SH, Tanner M, Keiser J. Artemisinins for schistosomiasis and beyond. Curr Opin Investig Drugs 2007; 8: 105-116.

93. Li YS, Chen HG, He HB, et al. A double-blind field trial on the effects of artemether on Schistosoma japonicum infection in a highly endemic focus in southern China. Acta Trop 2005; 96:184-190.

94. Hou XY, McManus DP, Gray DJ, et al. A randomized, double blind, placebo-controlled trial of safety and efficacy of combined praziquantel and artemether treatment for acute schistosomiasis japonica in China. Bull World Hlth Org 2008; 86: 788-795.

95. Gray DJ, McManus DP, Li Y, Williams GM, Bergquist $R$, Ross AG. Schistosomiasis elimination: lessons from the past guide the future. Lancet Infect Dis 2010; 10: 733-736.

96. Balen J, McManus DP, Li Y, et al. Comparison of two approaches for measuring household wealth via an asset-based index in rural and peri-urban settings of Hunan province, People's Republic of China. Emerg Themes Epi 2010; 7: 7 
97. Mutapi F, Maizels R, Fenwick A, Woolhouse M. Human schistosomiasis in the post mass drug administration era. Lancet Infect Dis 2017; 17 (2):e42-e48.

98. Lo NC, Addiss DG, Hotez PJ, et al. A call to strengthen the global strategy against schistosomiasis and soil-transmitted helminthiasis: the time is now. Lancet Infect Dis. 2017; 17 (2):e64-e69.

99.Tambo E, Ugwu CE, Guan Y, Wei D, Ning X, XiaoNong $X$. China-Africa Health Development Initiatives: Benefits and Implications for Shaping Innovative and Evidence-informed National Health Policies and Programs in Sub-saharan African Countries. Int J MCH AIDS 2016; 5(2): 119-133.

100. Adeline P. Mewabo, Roger S. et al. Assessing the prevalence of urogenital schistosomaisis and transmission risk factors amongst school-aged children around Mapé dam ecological suburbs in Malantouen district, Cameroon. Infect Dis Povert 2017 6:40.

101. Tchuenté LT, Rollinson D, Stothard JR, Molyneux D. Moving from control to elimination of schistosomiasis in sub-Saharan Africa: time to change and adapt strategies. Infect Diseases of Povert 2017 6:42.

102. Stothard JR, Campbell SJ, Osei-Atweneboana MY, et al. Towards interruption of schistosomiasis transmission in sub-Saharan Africa: developing an appropriate environmental surveillance framework to guide and to support 'end game' interventions. Infect Dis Povert 2017 6:10.

103. Hotez PJ, Pecoul B, Rijal S, et al. Eliminating the Neglected Tropical Diseases: Translat Scienc New Technol. PLoS Negl Trop Dis 2016; 10(3): e0003895. 